\section{TRICHINOSIS SIMULATING FRONTAL SINUSITIS}

\section{A REPORT OF THREE CASES}

EDWARD L. PRATT, M.D.

Assistant Visiting Surgeón, Vanderbilt Clinic, Department of Laryngology NEW YORK

During the past two years I have seen three cases of trichinosis, each referred as a probable case of frontal sinusitis. Two of these cases were seen in private practice and the third was referred to the Department of Laryngology at the Vanderbilt Clinic.

As is well known, the symptomatology of trichinosis is most variable. Most textbooks emphasize its resemblance at the onset to typhoid fever and its symptoms are usually classified under (1) intestinal or choleriform stage; (2) rheumatic or typhoid phase. It sometimes simulates appendicitis and is frequently called "rheumatism" - that facile term so often connoting only our ignorance. From a fairly comprehensive search of the literature I find no mention of cases simulating frontal sinusitis.

CASE I.-Mrs. B. R., aged 31, a physician's wife, was first seen with Dr. C. G. Coakley, Feb. 10, 1913. The patient at that time complained of a severe "coll in the head" excessive thick nasal discharge from both nares. and headache. Duration, three or four days. Examination revealed infection in hoth maxillary antrums. The antrums were cocainized and punctured beneath the inferior turbinates and a large amount of thick mucopurulent secretion was washed out of both antrums. The antrums were washed out daily for ahout ten days, when the patient was discharged cured. Patient remained apparently well until March 15, 1913, when she began to have pain in and about the left eye and left frontal region. In view of the fact that she had hut recently recovered from an infection in her antrums, her husband suspected that she might have frontal sinusitis and sent her in to the office. Examination of the nares revealed only a slight amount of congestion of the mucous membrane. Transillumination of the sinuses showed that the left frontal sinus illuminated well over a moderate sized area; the right frontal illuminated poorly over a very small area; the antrums illuminated equally and well. She was referred to Dr. E. W. Caldwell for roentgenograms of the sinuses and to $\mathrm{Dr}$ Joln E. Weeks for examination of the eyes. The roentgenograms showed an absence of a frontal sinus on the right side, a fronto-ethmoidal cell taking its place; on the left side the frontal sinus was of moderate size and of normal appearance. The antrums were also normal. Dr. Weeks reported the eye examination as negative. Nasal examination remained negative. It was now noted for the first time that the natient hacl an edema of both upper lids, but no edema elsewhere. Trichinosis was suspected and on questioning the patient it was learned that she had recently eaten pork and that she bad had a slight amount of muscular soreness in the region of the left deltoid insertion. She was sent to the Rockefeller Institute, where the diagnosis was confirmed and the following blood count reported: white blood cclls, 14,000; eosinophils, 22 per cent. The case ran a mild, uneventful course terminating in recovery.

CASE 2.-Mr. A. was referred to the nose and throa department of the Vanderbilt Clinic from the outpatient department of the Knapp Memorial Eye Hospital. He complained of pain in and about the left eye. As examination of the eyes at the hospital had been negative he was referred to the clinic as having a probable frontal sinusitis. Examination revealed an edema of both upper lids, more marked on the left than the right, but no edema elsewhere. Nasal examination was negative. His frontal sinuses illuminated equally and well as did also the antrums. A diagnosis of trichinosis was made and a differential blood count, maje at once in the college laboratory, showed 20 per cent eosinophils. This patient gave a history of having indulged freely in pork and also stated that he had had "rheumatism" in many of his long muscles. He was referred to the Presbyterian hospital but did not enter there and was consequently lost track of.

CAse 3.-Miss L. B. B., aged 32, a settlement worker, was referred to me by Dr. T. H. Russell on June 28, 1915. Patient had been ill for about a week, suffering from nausea and vomiting, pain in the right shoulder and in right chest posteriorly. Physical examination had been negative except that a small area of dulness was found in the right chest posteriorly; no change in the breath sounds, no râles or friction rubs were heard. On the day I saw her she ha: complained of pain in the region of the left upper lid and left frontal sinus, and as she had a slight "cold in th? head" it was thought well to eliminate the possibility of a: acute frontal sinusitis. Examination showed edema of both upper lids and a moderate amount of puffiness of the face, but no edema elsewhere. There was no muscular tenderness. Examination of the nose and accessory sinuses was negative. She gave a history of having eaten pork frequently. A diagnosis of trichinosis was made and a bloor count ordered. The count was as follows: white blood cells, 15,000; polymorphonuclears, 77 per cent.; lymphocytes, 16 per cent.; eosinophils, 6 per cent.; transitionals, 1 per cent. The next day she developed very severe muscular pains in both lower extremities and in the left wrist and left hand, and a moderate pericarditis. Vomiting persisterl and the patient was extremely ill for the next week. Tw: more counts were made at intervals of three days each and showed an increase of eosinophils, first to 14 per cent. and later to 22 per cent. Her symptoms gradually subsided and she made a complete recovery.

The diagnosis in all three cases rested on (1) edema of the lids (and in Case 3 of the face also) with absence of edema elsewhere; (2) negative nasal findings referable to the accessory sinuses; (3) the history; (4) the eosinophilia. It will be noted that in all these the "presenting symptom," as Cabot so well terms it, was pain in the region of the eye and frontal sinus; in only one case (Case 3 ) was the so-called choleriform stage present.

41 West Eighty-Third Street.

Chloroform in the Treatment of Insolation.-CASE 1.-. Man, aged 37, was found in a state of unconsciousness from insolation. After two hours of futile effort to revive the patient, I concluded to try chloroform as an experiment. I gave it very lightly for five or ten minutes by inhalation, and rapid improvement in symptoms occurred. This led me to further experiment in the two cases following.

CASE 2.-A robust, well-nourished boy, aged 4, after three hours of unconsciousness, was found with a temperature of 107, pulse above 200, stertorous respiration, profound stupor and complete relaxation. The patient was stripped of elothes and laid on a bed, and chloroform was administered cautiously by inhalation. No other treatment was given the first half hour. In twenty minutes the pulse had dropped to 160 , the respiration was quieted, and in half an hour the pulse was 145 , the temperature 105 , respiration was greatly improved, tonicity of muscles was returning, and the child manifested some return of consciousness. From this time on, the ordinary treatment was given with uneventful recovery.

CASE 3.-Man, aged 25, was overcome by heat while working in the hayfield in the afternoon. On arriving at $8 \mathrm{p} . \mathrm{m}$., I found the patient in a profound stupor and complete relaxation, pulse 165, temperature 106.6. Except for the removal of some light clothes, chloroform cattiously given by inhalation was the only treatment in the first half hour. Results were similar and equal to those in Case 2, followed by uneventful recovery under the ordinary treatment.

George C. Hanson, M.D., Charlson, N. D. 